\title{
The usability of videophones for seniors and hospice providers: a brief report of two studies
}

\author{
Debra R. Parker Oliver ${ }^{\mathrm{a}, *}$, George Demiris ${ }^{\mathrm{b}}$, Davina Porock ${ }^{\mathrm{c}}$ \\ ${ }^{a}$ School of Social Work, University of Missouri, 7/9 Clark Hall, Columbia, MO, USA \\ ${ }^{\mathrm{b}}$ Health Management and Informatics, School of Medicine, University of Missouri, Columbia, USA \\ ${ }^{\mathrm{c}}$ School of Nursing, University of Nottingham, Nottingham UK
}

Received 8 March 2004; accepted 6 July 2004

\begin{abstract}
This article uses a human factors evaluation framework to assess the usability of commercially available videophone technology. One study focuses on minimally functionally impaired seniors living in an assisted living facility. The second study focuses on usability for hospice staff. Seniors found the technology easy to use and were willing to accept the equipment in their homes, especially if requested by a healthcare provider. Administrators and hospice care providers also reported that the videophones were easy to use and would be of benefit to the patients they care for. The results indicate that videophones are a promising intervention with identifiable limitations.

(c) 2004 Elsevier Ltd. All rights reserved.
\end{abstract}

Keywords: Usability; Telemedicine; Seniors; Videophones; Hospice; Telehospice; Technology; Human factors model

\section{Introduction}

Critically important to the implementation of any technological innovation is the evaluation of its ease of use on the part of those it is designed to serve. Usability of new products is measurable and it is an essential feature of any technological intervention [1]. These two studies were a part of the Missouri Telehospice Project, focusing on the use of videophone technology with terminally ill hospice caregivers and patients.

\footnotetext{
This project was funded by the University of Missouri Research Council.

* Corresponding author. Tel.: +1-573-884-9639.

E-mail address: oliverdr@missouri.edu (D.R. Parker Oliver).
} 
Previous research has found high acceptance of videophone technology as an intervention by hospice professionals [2] and a readiness of hospice professionals to implement a telemedicine intervention [3]. The purpose of these studies was to assess the usability and acceptance of videophone technology first, by mentally competent, minimally functionally impaired seniors and second, by hospice professionals in preparation for a videophone intervention.

This work was based on the human factors evaluation approach advocated by Birkmire-Peters and colleagues [4]. The framework outlines four criteria for the evaluation of medical equipment: (1) technical acceptability, (2) operational effectiveness, (3) clinical appropriateness, and (4) equipment selection. Technical acceptability is assessed through interviews and observations. Operational effectiveness is demonstrated through training and proficient use of the equipment as well as considerations of time, tasks, errors, workload and user preferences. Clinical appropriateness assesses the reliability, validity and appropriateness of the equipment for the clinical setting it is designed for, and the actual selection of equipment should be based on the results of the other three criteria [4].

This conceptual framework laid the foundation for the following research questions. First, could the videophones technically meet the needs of connecting seniors with hospice care providers (technical acceptance)? Secondly, could the equipment be operated by frail older adults and hospice staff (operational effectiveness)? Finally, would hospice providers see value in the technology as a clinical intervention and would older adults accept videophone technology in their homes if it were recommended by healthcare professionals (clinical appropriateness)?

\section{Senior study}

\subsection{Methods}

Although the ultimate user of the Missouri Telehospice Project will be caregivers of terminally ill hospice patients, the research team felt that minimally impaired older adults would be a good simulation for the ultimate target population. The majority of hospice caregivers are spouses, and $80 \%$ of hospice patients are over the age of 65 [5]. These caregivers are known to be under tremendous stress due to the burdens of caregiving [6,7]. A decision was made to sample seniors with minimal functional limitations, living independently with moderate assistance, as an initial trial to test the usability of the equipment.

A demonstration booth was set up at a local senior assisted living facility in a Midwestern state. Two videophones were installed by researchers in different parts of the facility. Seniors were approached on their way to a congregate lunch and asked to try the videophone. Verbal informed consent was obtained from each participant before proceeding with the study protocol. Participants were instructed to dial the phone number of the researcher located in a different part of the facility and have a short discussion. They were given instructions on the basic use of the phone and told what they could expect from the demonstration. Participants dialed the identified phone number and were connected to the second researcher, who instructed them to "push the video connection button". After waiting for the video connection to link them to the other phone they were able to "see" the researcher on the other end of the line. Upon completion of the demonstration, each individual was asked their perception and experience using a questionnaire developed by the research team. Some participants requested assistance in reading and completing the questionnaire and this request was accommodated. 


\subsection{Findings}

This convenience sample resulted in 12 seniors participating in the study. The average age of participants was 85 years, ranging from 78-89 years. Thirty six percent of the participants were male, $64 \%$ female. All participants resided in the assisted living facility and were mentally competent to understand the instructions and provide feedback on their experience. All but one of the participants was able to complete the demonstration.

\subsubsection{Technical acceptability}

The videophones were easily installed, using currently available POTS (plain old telephone systems) lines and a nearby electrical outlet. The phone installation was simple, the traditional telephone was unplugged and the videophone plugged into the socket. The only concern noted is that the video component requires electricity so an electrical outlet must be located near the telephone outlet.

Observation of users with hearing impairments found they experienced difficulty with the equipment. Hearing aids that "ring" or "buzz" when using a regular telephone will react the same with the videophone, impeding the individual's ability to interact effectively. When the hearing aids were removed to prevent the interference, some individuals were able to hear with the volume adjusted, some were not. Another issue arose when individuals, accustomed to supplementing hearing loss with lip reading, were unable to read lips using the videophone due to the time delay in the transmission of the video signal with the audio signal. This seemed to frustrate some users as they continued to try and understand what they were hearing by monitoring the lip movements on the video display.

Technical malfunctions interfered on two occasions as the video connection failed and the demonstration was disrupted. In the first instance the participant was unable to connect and after two more attempts decided to quit the demonstration and have lunch. He stated he would return following lunch but did not. The next time the connection failed the participant was instructed to hang up and call back and the researcher successfully initiated the video connection.

\subsubsection{Operational effectiveness}

All but one participant was able to demonstrate use of the technology following simple verbal instructions from the researcher. As mentioned earlier, the unsuccessful participant was following directions but the video connection could not be established as a result of technical problems rather than participant error. Following the videophone interaction, participants were asked to complete a short questionnaire. Responses are summarized in Table 1.

Nearly three quarters of participants $(71 \%)$ reported that they strongly agreed the technology was easy to use. Only one individual found the technology difficult, and her hearing aids impeded demonstration as she experienced extreme interference. The overwhelming majority of the participants agreed or strongly agreed that the picture and sound were satisfactory. One participant had difficulty reading the numbers on the buttons, complaining that the color made them difficult to see.

\subsubsection{Clinical appropriateness}

To test the clinical appropriateness of the equipment, questions related to the comfort and acceptance of the equipment were asked. The majority of the participants reported they were comfortable using the equipment; it did not make them nervous and was not confusing. Ninety one percent stated that they would accept the technology in their home if requested by their healthcare provider. 
Table 1

Summary of responses to usability questionnaire by seniors $N=11$

\begin{tabular}{ll}
\hline Question & $N$ \\
\hline
\end{tabular}

1. Was the technology easy to use?

$\begin{array}{ll}\text { Strongly agree } & 8\end{array}$

Agree 2

Neutral

Disagree

Strongly disagree

$\%$

2. Was the picture quality satisfactory?

Strongly agree

Agree

Neutral

Disagree

Strongly disagree

3. Was the sound satisfactory?

Strongly agree

Agree

Neutral

Disagree

Strongly disagree

4. I am comfortable using the equipment?

Strongly agree

Agree

Neutral

Disagree

Strongly disagree

5. The equipment is not confusing.

Strongly agree

Agree

Neutral

Disagree

Strongly disagree

6. The equipment does not make me nervous.

Strongly agree

Agree

Neutral

Disagree

Strongly disagree

7. I would accept the technology if requested to by healthcare providers.

Strongly agree

Agree

Neutral

Observations of participants during the demonstration noted that individuals often smiled as they picked up the receiver, seeing themselves on the screen. They quickly commented on their personal appearance, pleased to see themselves until the video connection was established. Participants were comfortable 
talking to the researcher on the other phone, often joking with him and laughing. Overall seniors were very positive about the technology and found it easy to use.

Participants made several noteworthy comments during the demonstration. Statements related to their initial reactions, possible uses of the equipment, and the cost. Individuals had comments such as "great invention", "I'm really impressed with the picture", and "wonderful technology". Responses that suggested possible uses for the equipment included, "I would love to use it to see my grandchildren", "I would want to have it if I lived alone in a remote location", and "I would want to talk to my physician over this phone". Although one female firmly stated, "It will sell", another strongly noted, "I would not pay for it".

\subsubsection{Equipment selection}

The final usability criteria in the human factors framework, equipment selection, should be based on the results of the technical acceptability, operational effectiveness, and clinical appropriateness analysis [4]. The technology of various videophones is virtually the same, with the same manufacturer for all of the computer chips in each model. The differences between models involve a few features, including color and speakerphone capability. The results of the analysis of technical acceptability pointed out an important issue with color when one individual could not distinguish the numbers on the buttons due to the contrast in colors. This issue and the need for the ancillary features in different models are important considerations when choosing equipment.

\subsection{Discussion}

Despite the limitation of a small sample, this usability study identified several issues for consideration with a videophone intervention with seniors. Overall seniors successfully demonstrated use of the videophone and were supportive, interested, excited, comfortable, and willing to accept the technology into their home, however, there were some limitations. The videophone is not appropriate for individuals who suffer severe vision or hearing impairment. Individuals with hearing aids that interfere with normal telephone conversation will encounter the same problems with this equipment. Additionally, individuals who read lips to compensate for their hearing impairment may become frustrated with the video delays and the inability to link the lip movements with the voice they hear.

\section{Hospice provider study}

\subsection{Methods}

Using a similar format, an exploratory study with hospice providers used interviews, surveys, and observations following a demonstration of the videophone product. Because the ultimate intervention study was planned for the Midwest, the Midwest Regional Hospice and Palliative Care Conference was selected as the site for data collection. The conference was attended by 382 hospice professionals from seven Midwestern states. Researchers set up a demonstration booth in the conference exhibit area. Names of participants were entered into a prize drawing at the end of the conference in recognition for their assistance in the study.

Following verbal consent, the videophone was explained and the subjects were encouraged to handle the product. Researchers observed the nonverbal reactions of participants, answered questions, and asked 
for completion of a short structured survey. Administrators were interviewed with additional questions related to the costs and financial resources available to purchase the videophones.

\subsection{Findings}

A total of 63 (16.4\% of conference attendees) individuals participated in videophone demonstrations. The majority of participants (52.4\%) were social workers and nurses. Hospices represented served both rural and urban clients; $41.7 \%$ reported themselves as primarily rural hospice providers, $26.7 \%$ primarily urban, and the remainder as serving both urban and rural patients. Participants were experienced hospice professionals, working in the field an average of 5.2 years (range 1-15 years).

\subsubsection{Technological acceptance}

The evaluation of technological acceptance evaluated the ability of the videophone to connect the hospice professional to the caregiver effectively. This was assessed through interviews, observations of researchers, and the completion of a structured questionnaire following the demonstration. The results to the survey questions are summarized in Table 2.

Overall the hospice providers were very positive about the use of the technology with patients. Over $85 \%$ agreed that they could see a use for the videophones with patients. The majority $(88.8 \%)$ of those participating felt the technology was easy to use and the picture quality was satisfactory (96.9\%). Nearly three quarters of the participants felt that patients would accept the equipment in their homes (71.4\%) and would be able to understand the equipment (74\%). Patient understanding of the equipment was the only area where the hospice professionals showed concern as $4.8 \%$ expressed disagreement with the statement. Researchers observed positive nonverbal responses as the participants handled the videophone and asked questions regarding its operation.

\subsubsection{Operational effectiveness}

The ability of the equipment to operate effectively without problems and errors was found to be a concern in this project. The initial research plan was to connect the conference booth videophone to another unit in a hotel room within the conference hotel. This would have allowed participants the opportunity to interact with one of the researchers on the other end of the phone line, thus providing an assessment of the sound quality and connection issues in having a "virtual visit". This plan was modified when the hotel phone system would not allow point-to-point access through the phone system. The demonstration had to be done without a live connection, allowing the participant to touch the phone but not make an actual virtual visit. This experience indicates that the operational effectiveness of the intervention may be impacted if either party is in an institutional setting, for example an assisted care facility, whose phone system does not allow direct point-to-point connection.

Another issue related to the operational effectiveness of the innovation is the affordability of the technology and the willingness of individuals to pay the cost related to the equipment. In this study a follow-up interview was conducted with eight administrators of hospice programs. The majority of the administrators felt the technology would be useful in their agency and three quarters of them felt that the $\$ 500$ per unit cost was reasonable. A larger issue was the ability to afford the technology given the break even nature of their agency budgets. Half of the administrators reported that they were operating at a break even or very tight financial level and funding for the technology would have to come from 
Table 2

Summary of responses to structured questions $N=63$

\begin{tabular}{|c|c|c|}
\hline Question & $N$ & $\%$ \\
\hline \multicolumn{3}{|c|}{ 1. Technology is easy to use. } \\
\hline Strongly agree & 28 & 44.4 \\
\hline Agree & 28 & 44.4 \\
\hline Neutral & 4 & 6.3 \\
\hline Disagree & 0 & 0 \\
\hline Strongly disagree & 0 & 0 \\
\hline Missing & 3 & 4.8 \\
\hline \multicolumn{3}{|c|}{ 2. The picture quality was satisfactory. } \\
\hline Strongly agree & 35 & 55.6 \\
\hline Agree & 26 & 41.3 \\
\hline Neutral & 2 & 3.2 \\
\hline Disagree & 0 & 0 \\
\hline Strongly disagree & 0 & 0 \\
\hline Missing & 0 & 0 \\
\hline \multicolumn{3}{|c|}{ 3. I can see a use for this with my hospice patients. } \\
\hline Strongly agree & 25 & 39.7 \\
\hline Agree & 29 & 46 \\
\hline Neutral & 9 & 14.3 \\
\hline Disagree & 0 & 0 \\
\hline Strongly disagree & 0 & 0 \\
\hline Missing & 0 & 0 \\
\hline \multicolumn{3}{|c|}{ 4. My patients could understand this equipment. } \\
\hline Strongly agree & 12 & 19 \\
\hline Agree & 35 & 55 \\
\hline Neutral & 11 & 17.5 \\
\hline Disagree & 3 & 4.8 \\
\hline Strongly disagree & 0 & 0 \\
\hline Missing & 2 & 3.2 \\
\hline \multicolumn{3}{|c|}{ 5. My patients would accept this equipment. } \\
\hline Strongly agree & 15 & 23.8 \\
\hline Agree & 30 & 47.6 \\
\hline Neutral & 17 & 27 \\
\hline Disagree & 0 & 0 \\
\hline Strongly disagree & 0 & 0 \\
\hline Missing & 1 & 1.6 \\
\hline
\end{tabular}

fundraising activities. The majority indicated they would be willing to raise the money for the equipment if research found that it saved money or was proven to be an effective intervention.

\subsubsection{Clinical appropriateness}

The most important criterion for the human factors model is the reliability and validity of the innovation in a clinical setting [4]. Because a virtual connection could not be established we were unable to fully evaluate the system using this criterion. The questionnaire responses indicated perceived clinical value 
as over $85 \%$ of the hospice professional staff and $87 \%$ of administers interviewed reported they felt it would be useful for their patients. Further assessment is needed in this area and may only be known once a pilot project is implemented.

\subsubsection{Equipment selection}

The final criterion requires the assessment of the other variables in the selection of the specific equipment (Birkmire-Peters, 1999 \#784). The major limitation to the evaluation was the inability to connect the units through the hotel phone system and is unrelated to the specific product that might be chosen, rather is a noted limitation to the technology in general. This usability evaluation was limited because of the problems created with the institutional phone system, making the final equipment selection unfeasible with this specific study.

\subsection{Discussion}

Despite the limitations of the evaluation of specific criteria in the human factors model, this project indicates an overall positive response to the videophone technology by hospice professionals. The videophone technology is thought to be preferred over a voice over internet protocol (VoIP) due to the limited number of seniors with computers and broadband access, especially in rural Missouri. Staff and administrators see the technology as useful for their patients, easy to use, and acceptable. While funding might create challenges for the hospices, they are willing to accept the challenge if there is research supporting the outcomes of the intervention. The study demonstrates need for further usability testing and supports the feasibility of a demonstration project using videophone technology in the homes of hospice patients.

\section{Conclusions}

A comprehensive evaluation can be made for the usability of videophones when looking at findings from both of these studies. The data support the use of videophones with seniors and hospice providers, indicating it as a possible intervention tool. The findings from the two studies indicate that both seniors and hospice care providers perceive videophones as easy to use, valuable, and acceptable technology. Although both seniors and hospice administrators expressed financial concerns, it was also noted that the hospices would be willing to pursue fundraising sources if the equipment were found to be valuable to care delivery.

Limitations to videophone use involve technological issues requiring electrical outlets near phone connections and point-to-point telephone lines. Consideration of possible complications in hospice office phone systems needs to be a part of an intervention plan. Additionally, seniors with hearing aids that interfere with normal telephone conversation and those who rely on lip reading for communication are not suitable candidates for the technology. It is not known how many caregivers may suffer from these functional limitations and thus be unable to utilize the technology. Finally, attention must be given to the color of the numbers on the telephone so the user can more easily read them. While the technology for videophones is similar across styles, specific selection should consider the color contrasts of the features as an important variable in choosing a specific product.

With attention to the discovered usability limitations, videophone technology is a promising way for hospice caregivers to reach out to isolated elders and provide them with increased support. Further research 
is needed to assess the clinical outcomes derived from videophones; however, this study concludes the technology is usable for many older adults and hospice staff. Conclusions from both studies indicate videophones as a possible new tool for intervention in hospice care delivery.

\section{References}

[1] R.R. Mackie, C.D. Wylie, Factors influencing acceptance of computer-based innovations, in: M. Helander (Ed.), Handbook of Human-Computer Interaction, Elsevier Publishing Company, New York, 1988, pp. 1081-1106.

[2] G. Demiris, D. Parker-Oliver, D. Fleming, K. Edison, Hospice attitudes toward "Tele-hospice”, Am. J. Hospice \& Palliative Care, in press.

[3] D. Parker Oliver, G. Demiris, D. Parker Oliver, G. Demiris, An assessment of the readiness of hospice organizations to accept technological innovation, J. Telemed. Telecare 10 (2004) 170-174.

[4] D.P. Birkmire-Peters, L.J. Peters, L.A. Whitacker, A usability evaluation for telemedicine medical equipment, Telemedicine J. 5 (2) (1999) 209-212.

[5] National Hospice and Palliative Care Organization, NHPCO Facts and Figures. 2003.

[6] W.E. Haley, L.A. La Monde, B. Han, S. Narramore, R. Schonwetter, Family caregiving in hospice: effects on psychological and health functioning among spousal caregivers of hospice patients with lung cancer or dementia, Hospice J. 15 (4) (2001) $1-18$.

[7] S.C. McMillan, Quality of life of primary caregivers of hospice patients with cancer, Cancer Pract. 4 (4) (1996) 191-198. 